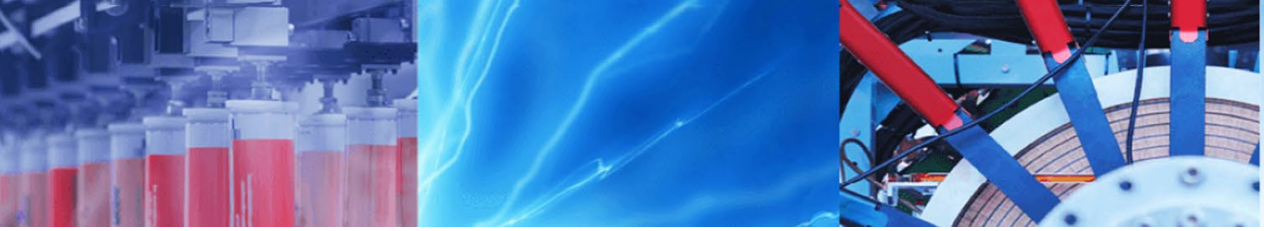

Research Article

\title{
Occupational exposure of librarians to mold spores and metal particles: a real-time case study
}

\author{
Alberto Baldelli ${ }^{1}$ D Brett Couch $^{2} \cdot$ Benjamin Loosley $^{3} \cdot$ Karen Bartlett $^{4}$
}

Received: 1 February 2021 / Accepted: 12 April 2021

Published online: 23 April 2021

(C) The Author(s) $2021 \quad$ OPEN

\begin{abstract}
In a university library, activities typical of librarians, such as unpacking boxes, removing books from the shelves, dusting, packing boxes, cataloguing, conservation and repair, photocopying, setting materials for class, and walking in a main hallway, were found to reduce indoor air quality through the production of airborne mold spores, metal dusts, and particulate matter of different size bins. Analyzing three libraries, the activity of conservation generated $9000 \mathrm{spores} / \mathrm{m}^{3}$ of mold spores, nearing the exposure limit of $10^{4}$ spores $/ \mathrm{m}^{3}$ reported for Penicillium sp., and silver nanoparticles of about $15 \mu \mathrm{g} / \mathrm{m}^{3}$, that over $8 \mathrm{~h}$ would exceed the occupational exposure limit of $0.19 \mu \mathrm{g} / \mathrm{m}^{3}$. For none of the activities, the levels of particulate matter with a diameter lower than $2.5 \mu \mathrm{m}\left(\mathrm{PM}_{2.5}\right)$ and $10 \mu \mathrm{m}\left(\mathrm{PM}_{10}\right)$ did not exceed the 8-h time weight average limits of exposure. However, by analyzing the 5 th percentile of the real-time $\mathrm{PM}_{10}$ data, values of about $1.5 \mathrm{mg} /$ $\mathrm{m}^{3}$, which is concerning for occupational exposure. Measuring real-time exposures of PM could generate an estimation of levels of mold spores and metal dusts in libraries. We demonstrate a high Spearman's rank correlation $(0.70)$ between the 5th percentile of PM with a diameter lower than $1 \mu \mathrm{m}$ and different metals. A high linearity $\left(R^{2}=0.85\right)$ is obtained between the total average of PM with a diameter lower than $10 \mu \mathrm{m}$ and mold spores $/ \mathrm{m}^{3}$.
\end{abstract}

Keywords Library · Indoor air quality · Mold spores · Metal nanoparticles · Particulate matter

\section{Introduction}

Indoor air quality (IAQ) is fundamental for the health of building occupants [20]. Libraries are unique indoor environment since they have a high density of occupants [40] and unique sources of pollutants, especially potentially harmful particulate matter (PM). Librarians spend at least $8 \mathrm{~h}$ per day [36] and frequently engage in activities that generate PM, such as dusting, handling books, cleaning, unpacking. In libraries, dusting shelves, removing books from shelves, repairing books, or packing and unpacking donation of books are examples of sources of PMs [27]. Few studies have estimated the sources of indoor pollutants in a library [31,33,39], the types of activities that are linked to a raise in PMs and the type of PM in libraries is lacking in the literature.

PMs are classified based on size, which is related to their ability to penetrate the respiratory system. Exposure limits and health effects vary for different PM classes. The sizes of PM are indicated with superscripts indicating the maximum diameter of particles in $\mu \mathrm{m}$ $\left(\mathrm{PM}_{10}, \mathrm{PM}_{4}, \mathrm{PM}_{2.5}\right.$, and $\left.\mathrm{PM}_{1}\right)$ [35]. $\mathrm{PM}_{10}$ can penetrate mostly in the upper part of a human respiratory system, and acute effects include coughing, wheezing, asthma attacks, bronchitis. Chronic exposure can result in high blood pressure, heart attack, strokes and premature

$\triangle$ Alberto Baldelli, baldelli.alberto@yahoo.com | ${ }^{1}$ Faculty of Food and Land Systems, University of British Columbia, Vancouver, Canada. ${ }^{2}$ Department of Botany, University of British Columbia, Vancouver, Canada. ${ }^{3}$ Safety and Risk Services, University of British Columbia, Vancouver, Canada. ${ }^{4}$ School of Population and Public Health, University of British Columbia, Vancouver, Canada. 
death [35]. Based on the latest recommendation of the United States Environmental Protection Agency (US EPA) and the Occupational Safety and Health Administration $(\mathrm{OSHA}), \mathrm{PM}_{10}$ has a permissible limit of exposure (PEL) $150 \mu \mathrm{g} / \mathrm{m}^{3}$ and a 24-h time weighted average (TWA) of $3 \mathrm{mg} / \mathrm{m}^{3}$ [14]. $\mathrm{PM}_{4}$ is referred as respirable since it can enter the lungs and can highly affect human health. Currently, no exposure limits are suggested for $\mathrm{PM}_{4} . \mathrm{PM}_{2.5}$ is also respirable and it is studied by the majority of references focused on IAQ $[16,24,29]$. PM 2.5 has a PEL of 24-h TWA of $35 \mu \mathrm{g} / \mathrm{m}^{3}$ according to US EPA [14]. TWA limits are useful to reduce the chronic exposure of occupants to different sizes of PMs but may not adequately account for short-term exposures. In certain cases, while the TWA limit is respected, short-term exposure limits are greatly exceeded $[6,7]$. Even though there are not current regulations on the $15 \mathrm{~min}$ TWA and ceiling limits for any size of PMs, cumulative exposure to levels of $\mathrm{PM}_{2.5}$ as low as $10 \mathrm{\mu g} / \mathrm{m}^{3}$ results in chronic occupational diseases such as asthma or cardiovascular disease [23, 26].

Setting exposure limits and recording PM in indoor environments are complex due to the diversity of types of PM in indoor environments. The PM size classes $(10,4$, and 2.5) include airborne mold spores that are ubiquitous in indoor and outdoor environments [12]. Even though precise measurements of mold spores in libraries are lacking in the literature, it is expected that, in indoor environments, up to 180 fungal species are capable of living on cellulose (the main component of paper). Given permissive moisture levels, paper can support the growth of fungi. Thus, libraries could contain a large number of mold spores from endogenous sources of fungal growth occurring on books [37]. Due to the variety of types of mold species, their impact on the occupants is uncertain [5]. Previous research studies identify Aspergillus, Cladosporium, Penicillium, Alternaria, and Chaetomium spp. as the main mold species contained in old books $[5,11]$. The first two species are also common outdoors and have a mild impact on the respiratory tract of an average healthy individual; when large numbers (on average $10^{6} \mathrm{spores} / \mathrm{m}^{3}$ ) of spores become airborne and can be inhaled, they pose a health hazard [22].

In general, concentrations of mold spores in an indoor environment with a clean HVAC supply system should be lower than the outdoor concentrations [28]. Buildings can be considered clean when the total counts of indoor mold spores are less than or equal to 2000 spores $/ \mathrm{m}^{3}$; counts of spores from the fungal genera Penicillium, Aspergillus, Cladosporium higher than 2000 indicate a possible indoor amplification due to mold growth and spore production [8] or endogenous sources of mold spores on contaminated material where active growth is no longer occurring [15].

SN Applied Sciences
Guidelines have been established for PM by several authorities, and there are guidelines for exposure of spores of particular fungal species but there is not a current guideline for the exposure to total mold spores. The difficulty of determining a general guideline for the exposure to mold spores relies on the differences between the species of molds and the differences between host reactions. Epidemiological studies have estimated the lowest observed effect levels (LOEL) for an 8-h exposure duration for airway inflammation $\left(10^{5} \mathrm{spores} / \mathrm{m}^{3}\right)$, nose irritation $\left(3 \times 10^{6}\right.$ spores $\left./ \mathrm{m}^{3}\right)$, and eye irritation $\left(10^{5}\right.$ spores $\left./ \mathrm{m}^{3}\right)$ [22]. Due to this intraindividual response to molds, it is important to frequently record and keep indoor levels of mold spores as low as reasonably achievable to avoid any sensitization of the occupants [10].

Typical activities performed by librarians can be linked to airborne mold spores and also to metallic particulate matter, PM; however, the lack in references makes this correlation interesting to be investigated [33]. Exposure to respirable metals (of sizes $\mathrm{PM}_{4}, \mathrm{PM}_{2.5}$, and $\mathrm{PM}_{1}$ ) like iron, aluminum, manganese, copper, lead, arsenic, and cadmium is connected with premature brain aging, neuroinflammation, stroke and possibly Alzheimer and Parkinson's diseases [18]. Metals are frequently present in libraries since they are used to preserve artistic and cultural heritage from acid hydrolysis due to the moisture present in the material, oxidation due to oxidative agents, biodeterioration due to the microorganisms, and photodegradation by UV irradiation due to the light. Hydroalcoholic suspensions of hydroxyapatite nanoparticles [19], zinc oxide [13], calcium hydroxide [30], magnesium hydroxide [17], silver nanoparticles [32], barium hydroxide [3], or titanium alcoholates [4] are the main substances involved in paper fabrication and preservation.

Some recent research studies have established regulations that are specific to each metal particulate. The OSHA recently updated the exposure limits to some of the metals that can be found in dust in typical libraries. For example, the OSHA PEL for total and respirable zinc dusts, is $10 \mathrm{mg} /$ $\mathrm{m}^{3}$ for 8-h TWA [2]. The American Conference of Governmental Industrial Hygienists (ACGIH) recently lowered the exposure limit to $2 \mathrm{mg} / \mathrm{m}^{3}$ for $15 \mathrm{~min}$ short-term exposure limit (STEL). Calcium-based compounds contained in indoor dusts include calcium carbonate, calcium hydroxide, calcium silicate, and calcium sulfate. Among these compounds, calcium hydroxide has the lowest OSHA PEL of $5 \mathrm{mg} / \mathrm{m}^{3}$ for 8 -h TWA. The same compound has a PEL of $2 \mathrm{mg} / \mathrm{m}^{3}$ for $15 \mathrm{~min}$ STEL. Dusts containing magnesium have to be limited to $10 \mathrm{mg} / \mathrm{m}^{3}$ of 8-h TWA for both OSHA and ACGIH. The exposure limit for silver particulates of any size is much lower; both OSHA and ACGIH determine as PEL $0.1 \mathrm{mg} / \mathrm{m}^{3}$ for 8 -h TWA. Barium-containing dusts are limited, by both OSHA and NIOSH, to $0.5 \mathrm{mg} / \mathrm{m}^{3}$ for 8 -h 
TWA PEL. OSHA determines the PEL to titanium particulates to be $15 \mathrm{mg} / \mathrm{m}^{3}$.

In this publication, we measured the levels of particulate matter of different size ranges that are produced by activities typically performed by librarians. Particulate matter, mold spores and metals generated by targeted activities were analyzed. Our quantification of airborne mold spores and metal nanoparticles generated by targetactivities indicates the potential of librarians in developing occupational diseases caused by PM generated during typical tasks. We suggest the need to regulate the limit of exposures to metal nanoparticles and fungal spores in libraries.

\section{Materials and methods}

\subsection{Facilities}

Two facilities located in a university were considered: the general library (GL) and the rare books and special collections (RB). The first facility is composed of three floors and a basement while the second is completely located in the basement of another building. On the third floor of the GL, the Technical Service is located. The Technical Service (TS) consists of a large and closed room where librarians commonly unpack and pack donations, catalogue new and old books, and restore the books. This room has limited access and has no connection with the outdoor. The remaining two upper floors of the GL are dedicated to book shelves and are opened to the public. These floors have more air exchange with the outdoor environment due to the presence of windows and doors. The basement of the GL is dedicated to book storage, and each room is isolated. The RB facility contains books that are aged between the sixteenth and the twentyfirst centuries. The RB facility has no contact with the outdoor. Measurements occurred between December 2019 and March 2020.

Table 1 shows additional information about the locations where the PM emitted by several activities was tested. In Table 1, the room name and size are reported. Indoor temperatures varied between 19 and $21^{\circ} \mathrm{C}$, and thus, the influence on the growth of molds is expected to be minor. Humidity affects mold growth in stored materials. In general, humidity levels should be kept below $65 \%$ to prevent germination of mold spores and growth of mycelium on materials varying in their hygroscopicity [9]. The minimum water activity $\left(w_{\mathrm{a}}\right)$ required for growth has been determined for Aspergillus niger $\left(w_{\mathrm{a}}=0.80\right)$, Cladosporium halotolerans $\left(w_{\mathrm{a}}=0.82\right)$, Penicillium rubens $\left(w_{\mathrm{a}}=0.82\right)[34]$.

Table 1 Details on the locations in which the particulate matter generated by different activities are recorded

\begin{tabular}{|c|c|c|c|c|c|}
\hline Facility & Room name & Description & $\begin{array}{l}\text { Room } \\
\text { volume } \\
\left(\mathrm{m}^{3}\right)\end{array}$ & Humidity (\%) & $\begin{array}{l}\text { Tem- } \\
\text { perature } \\
\left({ }^{\circ} \mathrm{C}\right)\end{array}$ \\
\hline GL-TS & NA & Shared room & 611 & 38 & 19 \\
\hline \multirow[t]{5}{*}{ GL } & Basement Storage room 1 & 12 movable stacks containing about 700 books each & 432 & 37 & 19.2 \\
\hline & Basement Storage room 2 & 12 movable stacks containing about 1000 books each & 410 & 30 & 23 \\
\hline & Main floor-modern meeting room & $\begin{array}{l}\text { No book present and a central table where donation } \\
\text { boxes are opened and reviewed }\end{array}$ & 96 & 32 & 21.5 \\
\hline & Main floor-old meeting room & 2 closed shelves containing 80 books which are opened & 45 & 33 & 21 \\
\hline & Second floor-studying area & 30 private desks and 20 shelves containing 100 books & 950 & 34 & 22 \\
\hline \multirow[t]{9}{*}{ RB } & Front desk & Librarians catalogue 30 boxes & 125 & 30 & 21.5 \\
\hline & Photocopying room & Small room containing only one photocopy machine & 6 & 32 & 25.5 \\
\hline & Classroom & $\begin{array}{l}\text { Close-doors room with } 10 \text { opened books from sixteenth } \\
\text { to eighteenth century }\end{array}$ & 50 & 32 & 20.7 \\
\hline & Storage room 1 & Small rooms containing 30 donation boxes & 24 & 39 & 16 \\
\hline & Automated storage room 2 & $\begin{array}{l}\text { Large room with } 30 \text { shelves including more than } 2000 \\
\text { books }\end{array}$ & 520 & 33 & 20.5 \\
\hline & Office area & $\begin{array}{l}\text { Shared room containing } 20 \text { working stations where } \\
\text { books are catalogued }\end{array}$ & 108 & 32 & 21.5 \\
\hline & Hallway & $\begin{array}{l}\text { Walking area where books can be deposited for a short } \\
\text { period of time }\end{array}$ & 17 & 32 & 20.5 \\
\hline & Conservation room 1 & Small room containing one working stations & 9 & 31 & 22.5 \\
\hline & Conservation room 2 & $\begin{array}{l}\text { Large and opened room containing three working sta- } \\
\text { tions }\end{array}$ & 23 & 33 & 20 \\
\hline
\end{tabular}

GL, woodward; TS, technical service, and RB, rare books and special collections 


\subsection{Sampling matrix}

Table 2 shows all activities grouped as background, unpacking boxes, removing books from the shelves, dusting, packing boxes, cataloguing, conservation and repair, photocopying, setting materials for class, and walking in a main hallway. These activities were selected due to their frequency in a librarian's routine. $\mathrm{PM}_{1}, \mathrm{PM}_{2.5}, \mathrm{PM}_{4}$, and $\mathrm{PM}_{10}$ and mold spores were measured per each of the activity listed in Table 2. Due to the probable link between the age of books and the presence of metals in or on the books, metal dusts were measured only for a few activities, as

Table 2 Description of all the activities considered in this project

\begin{tabular}{|c|c|c|c|c|c|}
\hline Activity & Description & Location & Person \# & h per week & Metal dust \\
\hline \multirow[t]{7}{*}{ a. Back-ground } & 1. Presence of openings in GL & Outdoor & NA & NA & \\
\hline & 2. The largest room of the $\mathrm{GL}$ & $\mathrm{GL}-$ main floor & NA & NA & \\
\hline & \multirow[t]{2}{*}{ 3. Visible presence of airborne PMs } & $\mathrm{GL}$-storage room 1 & NA & NA & $x$ \\
\hline & & $\mathrm{GL}$-storage room 2 & NA & NA & \\
\hline & 4. WD-TS is a large opened space & TS—kitchen area & NA & NA & $x$ \\
\hline & $\begin{array}{l}\text { 5. The RB has opened doors in most of the } \\
\text { facility, located in a basement }\end{array}$ & $\begin{array}{l}\mathrm{RB} \text { - studying shared } \\
\text { room-no occupant }\end{array}$ & NA & NA & $x$ \\
\hline & 6. The storage room 2 in $\mathrm{RB}$ is closed & $\mathrm{RB}$-storage room 2 & NA & NA & \\
\hline \multirow[t]{5}{*}{ b. Unpack donation boxes } & 1. 20 Asian books shipped from U.S.A & TS & 5 & 4 & \\
\hline & 2. 20 books shipped from New Delhi & TS & 3 & 0.3 & \\
\hline & 3. Local donation -10 books & $\mathrm{RB}$-storage room 1 & 2 & 1.5 & $x$ \\
\hline & $\begin{array}{l}\text { 4. } 20 \text { books } 1980 \text { s, } 5 \text { books 1800s, } 5 \text { books } \\
1990 \text { s and } 5 \text { books 2000s }\end{array}$ & $\mathrm{GL}-$ modern meeting room & 1 & 1 & \\
\hline & 5. Reading receipt of 40 donated books & TS & 5 & 2.5 & \\
\hline \multirow[t]{5}{*}{ c. Remove books from shelves } & 1. 15 books between 1780 to 1840 & GL_storage room 1 & 8 & 0.25 & $x$ \\
\hline & 2. 15 books between 1850 to 1940 & GL_storage room 2 & 8 & 0.25 & $x$ \\
\hline & 3. 10 books older than 1980 & $\mathrm{GL}$-second floor & 4 & 2 & \\
\hline & 4. Manually removing 10 books & $\mathrm{RB}$-storage room 1 & 7 & 2.5 & \\
\hline & 5. Automatically removing 40 books & $\mathrm{RB}$-storage room 2 & 6 & 3 & $x$ \\
\hline d. Dust & 1. Dusting on the surface of books & $\mathrm{GL}$-second floor & 2 & 2 & $x$ \\
\hline \multirow[t]{3}{*}{ e. Pack boxes } & 1. Tattle tapping -50 to 70 books & TS & 5 & 2 & \\
\hline & 2. Labeling -50 to 70 books & TS & 5 & 7 & \\
\hline & 3. Packing -5 boxes and 70 books & TS & 5 & 7 & \\
\hline \multirow[t]{6}{*}{ f. Catalogue } & 1. Book younger than $2000-20$ books & TS & 7 & 2.5 & \\
\hline & 2. Books older than $1800-20$ books & TS & 3 & 6 & $x$ \\
\hline & 3. Signing out material -15 books & $\mathrm{RB}$ 一front desk & 5 & 10 & \\
\hline & 4. 15 books of various origins and ages & Office area & 10 & 3 & \\
\hline & 5. Browsing 10 books -1800 to 1900 & $\mathrm{GL}$-old meeting room & 1 & 0.02 & $x$ \\
\hline & 6. Binders 30 articles -2010 and 2020 & GL_office area & 1 & 3 & \\
\hline \multirow[t]{5}{*}{ g. Conservation-repair } & 1. Mending 12 books older than 1800 & TS & 2 & 7 & $x$ \\
\hline & 2. Checking 20 books older than 1800 & TS & 1 & 2 & $\mathrm{x}$ \\
\hline & $\begin{array}{l}\text { 3. Conservation of damages pages from } \\
10 \text { books older than } 1800\end{array}$ & RB-conservation room 1 & 2 & 5 & $x$ \\
\hline & 4. Repairing books younger than 1900 & BL_office area & 1 & 8 & \\
\hline & $\begin{array}{l}\text { 5. Checking visible mold on } 10 \text { books } \\
\text { older than } 1700\end{array}$ & $\mathrm{RB}$-conservation room 2 & 1 & 15 & $x$ \\
\hline \multirow[t]{2}{*}{ h. Photocopy } & 1. 10 books older than 1800 & $\mathrm{RB}$ & 2 & 5 & \\
\hline & 2. 10 items younger than 2000 & GL_office area & 5 & 3 & \\
\hline i. Class & 1. Setting up 10 books - 1700 to 1900 & $\mathrm{RB}$ & 1 & 1 & $x$ \\
\hline j. Hallway & 1. Walking through & RB & 15 & 2 & \\
\hline
\end{tabular}

Particulate matter (PM) and mold spores were measured for all activities, while metal dusts are shown in the last column. Background measurements were taken for each location

$\mathrm{GL}$, woodward; TS, technical service, $\mathrm{RB}$, rare books and special collections 
shown in the last column in Table 2. Information such as the number of people and the hours per weeks involved in each activity is shown in Table 2. This information was obtained by questioning 17 librarians.

Background measurements were taken for $\mathrm{GL}, \mathrm{TS}$, and RB. The sampling sites were the main study room on the main floor of GL, the kitchen area of TS, and the studying area close to the entrance of RB. While TS is a large shared room with no doors and no opened windows, the GL and the RB contain closed rooms such as storage rooms.

Library staff unpack donation books ( $3 \mathrm{~h}$ per week). This activity includes opening boxes, removing the contained books, briefly checking the books status, and recording the books receipts. The origin and the age of the books are expected to influence the amount of particulate matter contained in the box. Librarians remove requested books from the shelves ( $3 \mathrm{~h}$ per week). The librarians verify the identity and the quality of the book by opening the book and quickly examining it. Books on shelves also need to be cleaned and dusted $(\sim 3 \mathrm{~h}$ per week); librarians prepare boxes filled with books to ship to other libraries or facilities ( $2 \mathrm{~h}$ per week). The librarian quickly examines each book, labels them, and places them in a cardboard box.

Cataloguing includes browsing each book and labeling them ( $7 \mathrm{~h}$ per week). The conservation and repair of old or damaged books are performed on average for $6 \mathrm{~h}$ a week. This activity involves the use of cutters, to reshape some pages, glue, to adhere detached pieces, water, to flatten the books' pages, and rarely bleach or detergent to remove a visible mold growth. Librarians photocopy books or parts of books ( $4 \mathrm{~h}$ per week). In special libraries, such $\mathrm{RB}$, lectures take place due to the presence of interesting and rare documents. Library staff commonly spend $\sim 1 \mathrm{~h} \mathrm{a}$ week checking and preparing the materials for lectures. It can be estimated that librarians walk through major hallways for about $5 \mathrm{~h}$ per week. Books can be stored on carts on the side of major hallways for a total of 1 day per week.

\subsection{Statistical analysis}

Each sample, both for PM and for mold spores, was collected three times. Average, standard deviation, and standard errors are derived by the differences in the collection times. Moreover, in order to establish correlation between two variables, a Spearman's rank correlation was performed.

\subsection{Collection procedures and analytical techniques}

Collection and analytical techniques differ according to the pollutant measured: particulate matter (PM), mold spores, or metal dusts. PM and mold spores were collected simultaneously. The collectors for PM and mold spores and the collectors for metal dusts were placed $5-10 \mathrm{~cm}$ from the source of the pollutants.

\subsubsection{Particulate matter (PM)}

PM was recorded in real time using a DustTrak (DRX) Aerosol Monitor 8533 (TSI Inc., MI, USA). This device has an accuracy of $1 \mu \mathrm{g} / \mathrm{m}^{3}$ for sampling at an airflow rate of $1 \mathrm{~L} /$ min; the flow rate was calibrated at each use using a highefficiency particulate filter. Collection times were set at 25-30 min per each activity listed in Table 2.

\subsubsection{Mold spores}

2.4.2.1 Qualitative assessment of molds on contaminated books As part of a conservation and repair activities in the RB (Table 2), a qualitative assessment of the mold contamination was performed on water damaged, moldcontaminated books. Visible mold on book surfaces was sampled by culturing and tape lifts. Molds were identified by microscopic examination. Book surfaces were sampled by swabbing the book surfaces with a sterile cotton swab and streaking across the surface of sterile malt agar (MA) plates ( $20 \mathrm{~g}$ malt extract; $15 \mathrm{~g}$ agar; $1 \mathrm{~L}$ distilled water; autoclaved $21 \mathrm{~min}$ at $121^{\circ} \mathrm{C}$ ) and incubating on the benchtop. Surfaces were sampled for the presence of spores and spore producing structures by pressing $a \sim 3 \mathrm{~cm}$ length of $1 / 2$ " double sided tape $\left(3 \mathrm{M}, \mathrm{Scotch}^{\oplus}\right)$ against the surface of books. Microscopic examination was performed using Axiostar plus microscope (Zeiss) fitted with a Power Shot A620 AiAF camera (Canon). Brightness, contrast and levels of images were adjusted using Adobe Photoshop CC 9.0 (Adobe Systems Inc.). Samples on tape mounts were stained with $0.05 \%$ Analine blue in lactic acid.

2.4.2.2 Airborne Zefon ZBP-205 Bio-Pump Plus (Zefon International, Florida, USA) was used to sample airborne mold spores. Mold spores were collected at a height of one meter and a half and at a distance of $30 \mathrm{~cm}$ from the operator. Three samples per each activity shown in Table 2 were collected. Collection times were set between 25 and 30 min per each activity shown in Table 2 . A flow rate of $15 \mathrm{lpm}$ conveys particulates of any size on an Air-O-Cell cassette containing a glass slide. A calibration of the flow rate was performed for every location tested. Mold spores and other dust particles were deposited on a glass slide. One droplet of lactophenol cotton blue was placed on the collection slide. The lactophenol was allowed to dry and a drop of immersion oil for light microscopy was placed directly on the sample. Samples were observed with a microscope with an objective lens of $50 \times$ and a total magnification of $500 \times$. The number of mold spores $(N)$ was 
counted by randomly selecting different fields ( $n$ ) of the samples. The random selection was achieved by scanning each sample using the same pattern, which was a zig-zag' line starting from the top left of each sample and finishing in the bottom right. The number of fields examined varied between 17 and 20 . The mold spores were differentiated from the other particulates based on uniformity and color. Mold spores tend to have a more uniform, often spherical or elliptical, shape compared to other particulates contained in indoor dust and are blue or brown after staining. The number of samples per $\mathrm{m}^{3}$ (spores $/ \mathrm{m}^{3}$ ) was determined by using

$\frac{\text { spores }}{\mathrm{m}^{3}}=\frac{N A}{n a V}$

where $A$ is the deposition area of $16.5 \mathrm{~mm}^{2}, a$ is the total field area observed microscopically, and $V$ the volume calculated from the flow rate of $15 \mathrm{lpm}$. This methodology resolves a maximum of 400 spores per field and has a lower limit of detection (LOD) of 11 spores $/ \mathrm{m}^{3}$.

\subsubsection{Metal dusts}

Metal dusts were collected after the collection of mold spores for selected activities (Table 2). Six chemical elements were analyzed: barium (Ba), calcium (Ca), magnesium $(\mathrm{Mg})$, silver $(\mathrm{Ag})$, titanium $(\mathrm{Ti})$, and zinc $(\mathrm{Zn})$. These chemical elements were selected due to their presence in book conservation. A collection time of 25-30 min was used. A PVC filter of $37 \mathrm{~mm}$ was placed inside a SKC $37 \mathrm{~mm}$ cassette (SKC Inc., Pennsylvania, USA). Two samples were collected for the activity shown in the last column of Table 2. These cassettes were placed in the Zefon BioPump. Each filter was pre- and postweighed in a preconditioned balancing room, set at $20^{\circ} \mathrm{C}$ and $35 \%$ of humidity. Weights of PMs collected using Zefon pump were compared with DustTrak measurements to determine the amount of PM with a cutoff diameter larger than $10 \mu \mathrm{m}$ (largest size recordable using the DustTrak). A Rigaku NEX CG was used to determine the amount of selected airborne metals. Standard reference films were used for each metal detected. Results from the XRF analysis are reported in $\mu \mathrm{g} / \mathrm{cm}^{2}$.

\section{Results and discussion}

The particulate matter (PM) that a librarian can inhale while performing common tasks was quantified and analyzed. Pollutants produced by typical activities performed by a librarian were monitored.

\subsection{Real-time distribution of particulate matters (PMs)}

The impact of PMs can differ according to their size; the most common sizes analyzed in indoor $\mathrm{PMs}$ are $\mathrm{PM}_{1}$, $\mathrm{PM}_{2.5}, \mathrm{PM}_{4}$, and $\mathrm{PM}_{10}$. The importance of the distribution of these PM sizes over time has been emphasized by previous studies [7] for other types of indoor environments. By defining the cause of spikes in PMs emissions, the importance of the use of personal protective equipment (PPE) can be determined and guideline for the reduction of the emission sources can be established.

Figure 1 shows two examples of real-time measurements of PM emissions from the activities of (a) taking books aged from 1850 to 1940 from shelves and (b) opening a donation box containing 10 books varying in age and origin. Each time a book is taken from the shelf, checked and opened, a spike in all PM sizes can be seen (Fig. 1a, b). The highest peak in PM, up to $6 \mathrm{mg} /$ $\mathrm{m}^{3}$, is seen when the donation box is opened (Fig. 1b). Even though the 8-h TWA was not exceeded, repetitive exposures to high and sudden peaks of $\mathrm{PM}_{2.5}$ or $\mathrm{PM}_{10}$ are shown to impact the, eye, nose, throat and lung irritation, coughing, sneezing, runny nose and shortness of breath [38].

Due to the sharp changes in PM emissions from each activity, two parameters have been derived from the realtime PM measurements: "average" and "5th percentile." These averages have been used in previous studies to correlate the PM exposures with bioaerosols, such as allergens [7]. Since the OSHA TWA $8 \mathrm{~h}$ limits of exposure (for $\mathrm{PM}_{2.5}$ and $\mathrm{PM}_{10}$ the 8 -h TWA are 15 and $5 \mathrm{mg} / \mathrm{m}^{3}$, respectively) are not exceeded by the average measurements, it is important to detect the ceiling limits to prevent any health effects to the librarians. In fact, time-average levels refer to the whole minute-by-minute data collected per each activity. The so-called ceiling limits refer to the average of the upper 5 th percentile of the minute-by-minute data collected per each activity, in Fig. 1. The difference between the two types of average is shown in Fig. 2. As expected, the "average" values are always lower than the values of "5\%." This gap shows that, in almost all activities tested, spikes in the PM emissions are present [6]. The highest gap is encountered when the higher averages of $\mathrm{PM}_{10}$ of any size are measured, which are in the activities of unpacking boxes (100\%), removing books from the shelves (130\%), and conservation repair (50\%). All the other size bins of the PM are higher in case of the " $5 \%$." This indicates that the smaller size bins, $\mathrm{PM}_{1}$ and $\mathrm{PM}_{2.5}$, that are of a higher occupational risk, are higher if only spikes in PM emissions are considered. Higher $\mathrm{PM}_{1}$ and $\mathrm{PM}_{2.5}$ in the $5 \%$ of the average values are of interest if metals are found in the aerosolized dust. Due to the lack of regulations for metal 


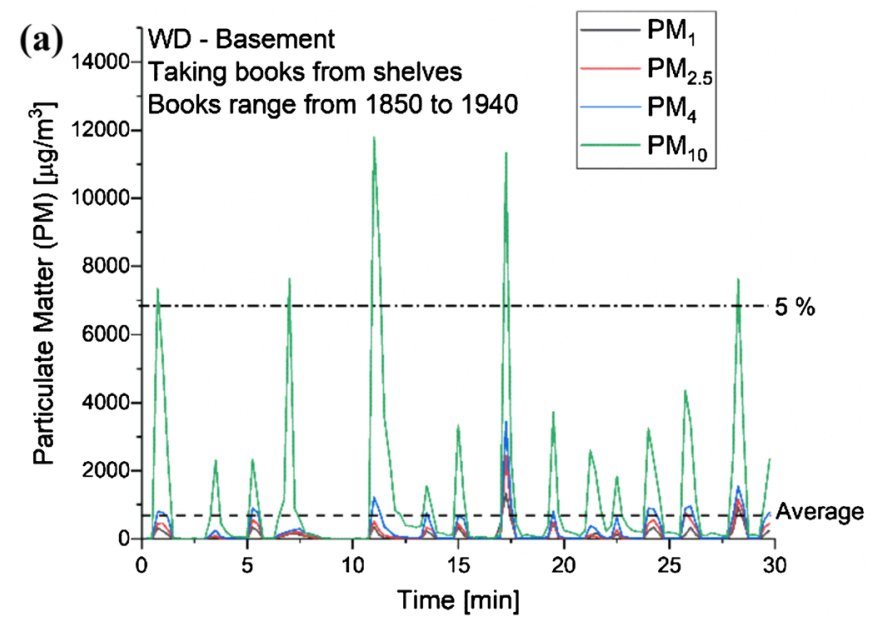

Fig. 1 Examples of real-time measurements of PM of different sizes $\left(\mathrm{PM}_{1}, \mathrm{PM}_{2.5}, \mathrm{PM}_{4}\right.$, and $\mathrm{PM}_{10}$ have a diameter lower than 1, 2.5, 4, and $10 \mu \mathrm{m}$, respectively). The example in a represents the activity of "taking books from shelves" measured in storage room 1, located

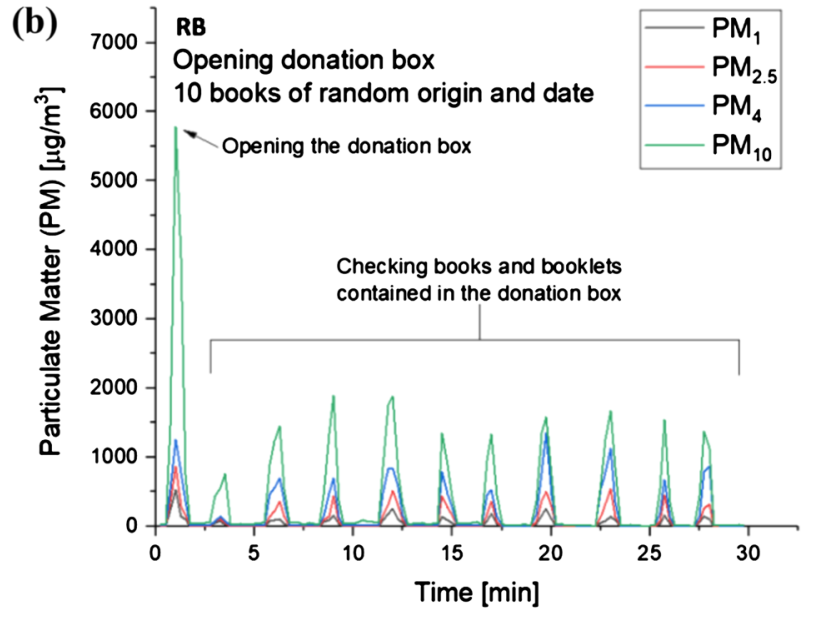

in the basement in (BL) facility. The example $\mathbf{b}$ represents "opening donation box" measured in storage room 2 in the rare books and special collections (RB) facility

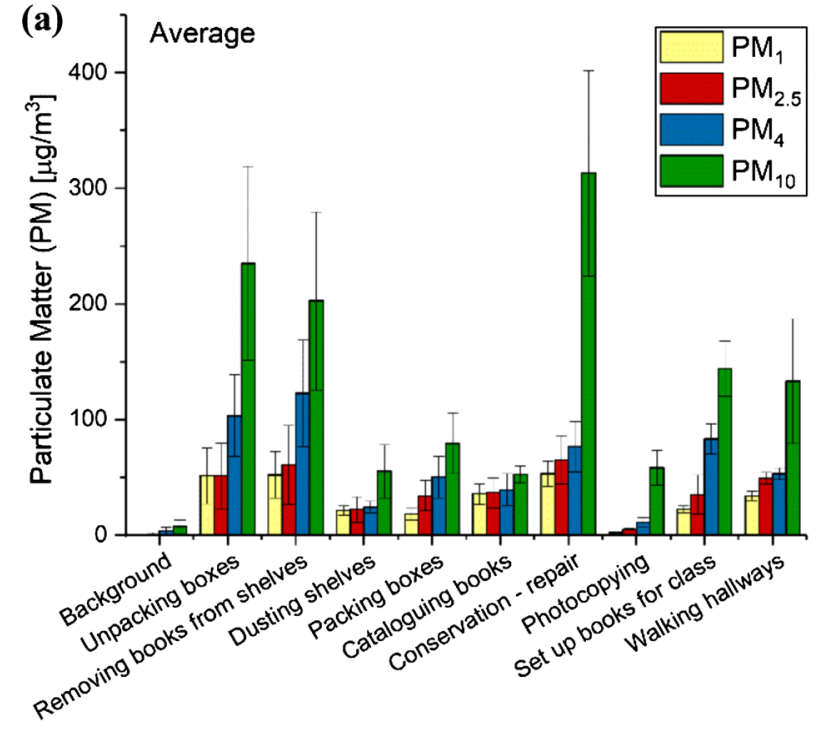

Fig. 2 Levels of particulate matter of different sizes $\left(\mathrm{PM}_{1}, \mathrm{PM}_{2.5}\right.$, $\mathrm{PM}_{4}$, and $\mathrm{PM}_{10}$ ) per each activity. The average of all minute-by-minute data "average" and the average of the 5 th percentile of the data " $5 \%$ " per each activity are shown in $\mathbf{a}$ and $\mathbf{b}$, respectively. OSHA

nanoparticles, it is of particular interest for the prevention and reduction of occupational exposure.

\subsection{Mold spores}

Mold spores were identified both on the surface of books and in air samples. Molds on the surface of books are expected to be a major contributor to spores present in the air as particulate, especially in cases where conservation

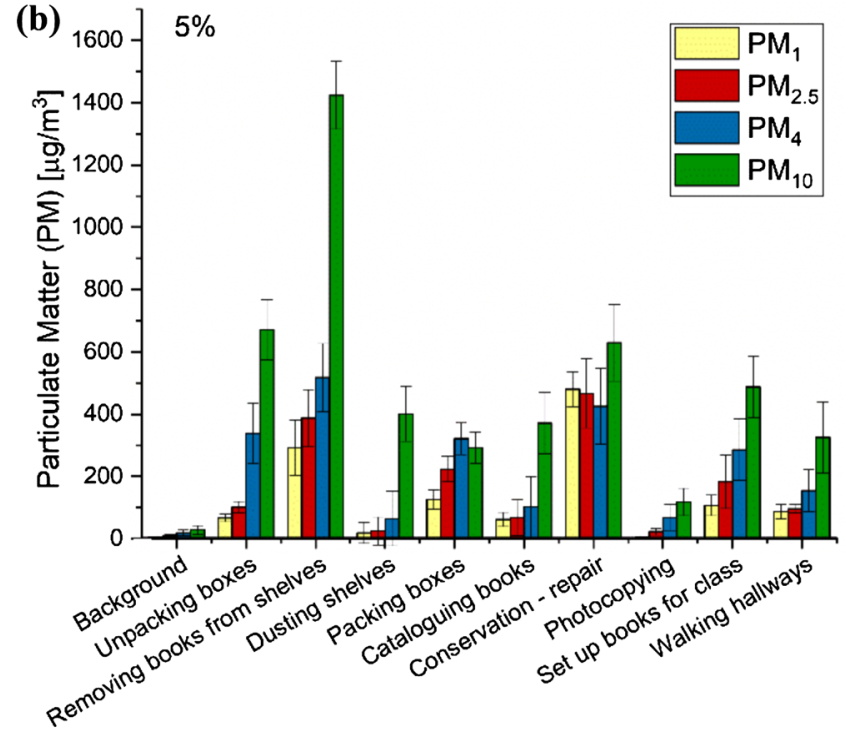

exposure levels are not shown since much higher than detected PM levels (for $\mathrm{PM}_{2.5}$ and $\mathrm{PM}_{10}$, the TWA 8-h exposure limits are 15 and $5 \mathrm{mg} / \mathrm{m}^{3}$, respectively)

efforts are being performed on mold-contaminated books. Abundant spores were observed on the surface of plates containing the swabs from three out of four books. The spores germinated within a day of sampling; germination rate was not quantified. The cultured molds were all Penicillium sp. with the exception of one sample which contained Mucor. Inhalation of Mucor or Penicillium spores can generate similar health risks, such as coughing, chest pain, shortness of breath, and, in the worst cases, pneumonia 
[21]. Table 3 summarizes culture-based sampling of contaminated books.

Tape lifts were made from areas of book \#1 where molds had been observed prior to cleaning. Branched, Penicillium-like conidiophores and chains of small, $3 \mu \mathrm{m}$ $(n=8)$ round spores were observed in tape lifts from book \#1. Although the culture-based method of sampling employed is biased towards fast growing species (like Penicillium sp.) and will not capture slower-growing or less abundant species, the results of the tape lifts further suggest that the molds contaminating these books were Penicillium sp. As air sampling for fungal spores occurred during the time when books were being handled for swabbing and making tape mounts, spores of Penicillium sp. were expected to be a major component of the airborne spores in the conservation area 2 of the RB facility at this time (Fig. 3).

Contaminated books are potentially an important endogenous source of airborne mold in a library and airborne spores (especially for species like Penicillium sp. producing dry chains or droplets of spores) are expected to be generated when handling these books [9]. Therefore, it is important to verify the risk for librarians to develop occupational diseases.
Figure 4 shows some examples of the airborne mold spores collected for the activities of "taking books from the shelf" in storage room 2 in WD are shown in (b), from the activity of "unpack donation boxes" in storage room 1 in WD (c), and "taking books from the shelf" at the second floor of WD. By comparing the results shown in Figs. 4 and 5 , we can estimate that the airborne mold spores can be Penicillium sp. only for the activity of conservation and repair in the RB facility. The health risks derived by its short-term exposure are not considered high. Long-term exposures to airborne Penicillium sp. can result in development of allergies. While it remains challenging to correlate the spores count and the occupational allergy, Lin et al. determine that 10 spores $/ \mathrm{m}^{3}$ of Penicillium sp. are enough to exacerbate allergic symptoms in a person sensitive to fungal allergens [25]. In any case, it is not possible to correlate molds sampled and identified from potential sources with air sampling in other facilities. Thus, the health risks derived by short or long-term exposures to high content of mold spores are unknown and, for such, they should be taken into consideration.

Due to the lack of regulations on the exposure limits to any airborne spore type, it is challenging to connect the number of spores per $\mathrm{m}^{3}$ to potential effects to library staff
Fig. 3 Penicillium-like conidiophores from a tape mount from book \#11 stained with $0.05 \%$ Analine blue in lactic acid. The arrow indicates the branched conidiophore. Scale bars are $10 \mu \mathrm{m}$ and $3 \mu \mathrm{m}$ (a). Chains of spores from a tape mount from book \#1 stained with $0.05 \%$ Analine blue in lactic acid. Scale bars are $10 \mu \mathrm{m}$ and $3 \mu \mathrm{m}$ (b) (a)

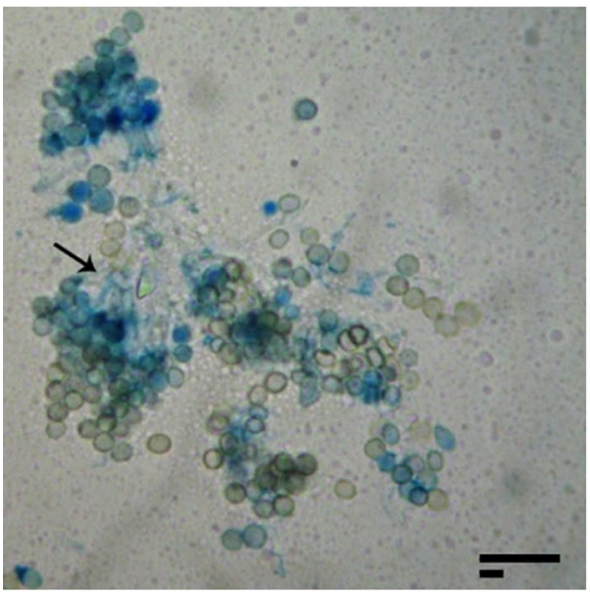

(b)

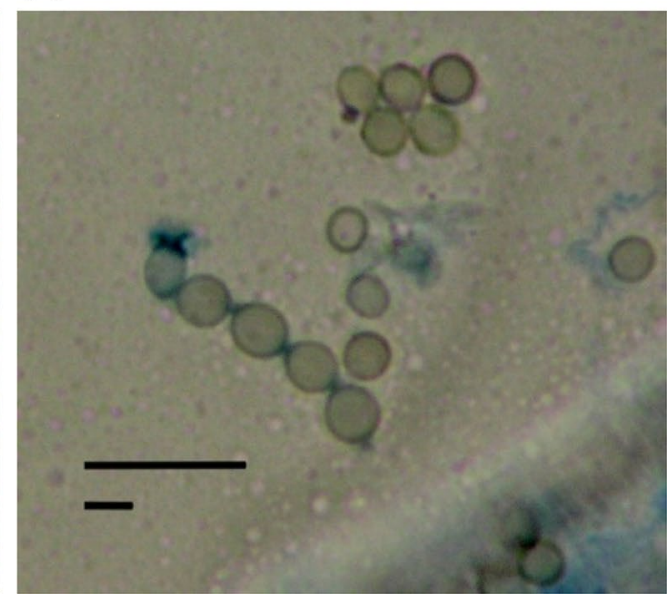

Table 3 Summary of culture results and microscopic identification of molds from contaminated books

\begin{tabular}{llll}
\hline Book \# & $\begin{array}{l}\text { Location of swabbed } \\
\text { surface }\end{array}$ & Culture results & Mold identification \\
\hline 1 & Surface & & Penicillium sp. \\
& Interior & Confluent growth of blue-green colonies after 5 days & Penicillium sp. \\
2 & Surface & Confluent growth of blue-green colonies & Penicillium sp. \\
3 & Surface & Multiple, $\sim 58$, blue-green colonies but not confluent growth & Penicillium sp. \\
& & Confluent growth of blue-green colonies. Additional colonies produc- & Mucor sp. \\
& Surface & ing sporangia & Penicillium sp. \\
\hline
\end{tabular}


Fig. 4 Examples of mold spores recognized under a light microscope. Samples collected from the activity of "conservation and repair" in the office are in RB (a), from the activities of "taking books from the shelf" in storage room 2 in WD are shown in $\mathbf{b}$, from the activity of "unpack donation boxes" in storage room 1 in WD (c), and "taking books from the shelf" at the second floor of WD (d)

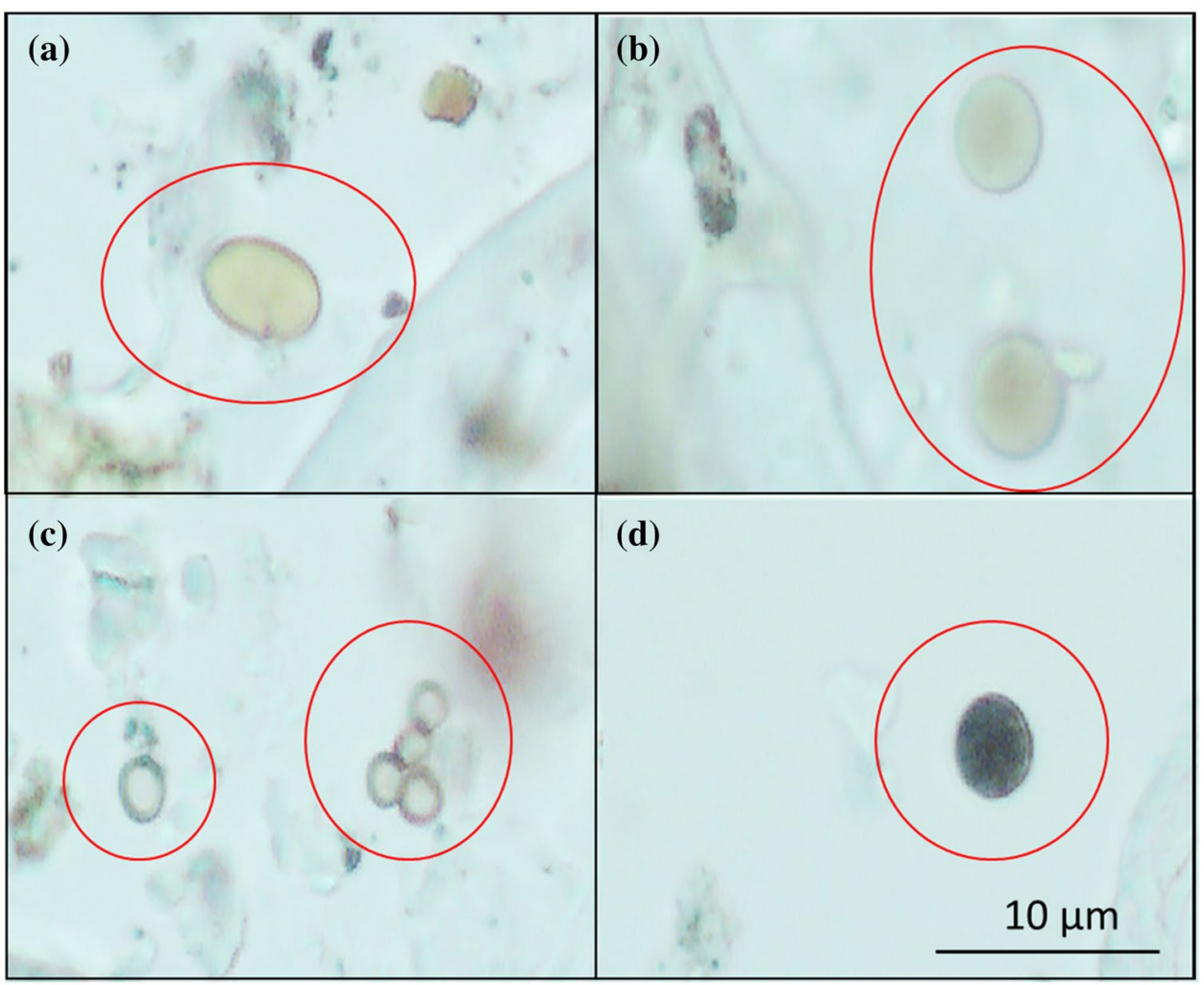

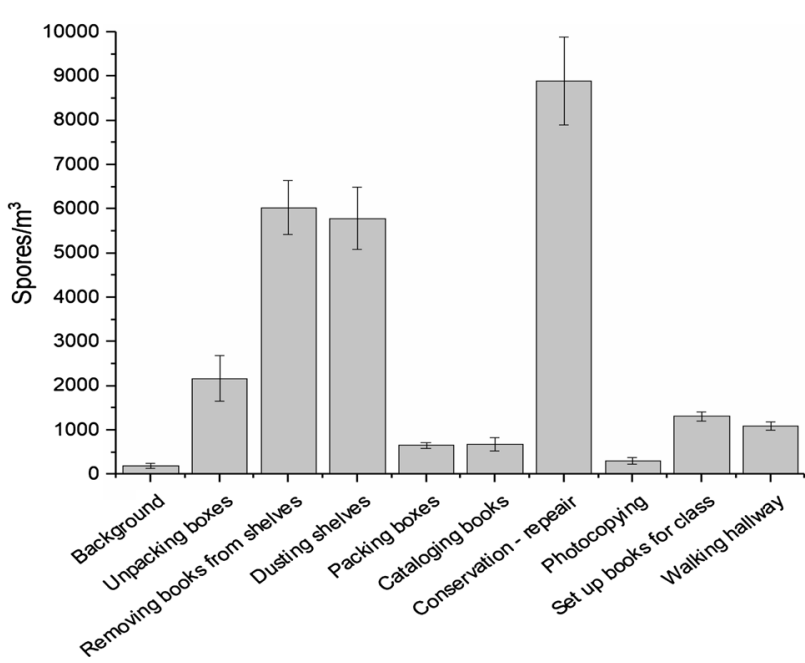

Fig. 5 Spore count per $\mathrm{m}^{3}$ generated by each activity. Error bars are generated by the differences in the measurements obtained in different locations and in repeated activities. The exposure limits to mold spores are not shown in the plot because set at $10^{5} \mathrm{spore} / \mathrm{m}^{3}$

health. It is of a common expectation that higher numbers of airborne mold spores show a tendency of a more probable development of allergic symptoms in a healthy person. The highest number of airborne mold spores is identified in the activities of conservation and repair, removing books from shelves, and dusting shelves, in Fig. 5a. Even by considering differences in operators and facilities, the number of spore counts generated by these three activities remains fairly high. This result suggests that a librarian, when performing these three activities, is exposed to counts of mold spores higher than 5000 spores $/ \mathrm{m}^{3}$; therefore, the use of personal protective equipment (PPE), such as a facial mask, is recommended. In particular, in the RB facility, the activity of conservation and repair generates a spore count per $\mathrm{m}^{3}$ is almost 10,000 . In this activity, these spores might be Penicillium sp. as shown in Fig. 4.

The activities of unpacking boxes, packing boxes, cataloguing books, set-up materials for class, and walking hallway resulted in lower exposure, exposure is still $500 \mathrm{spores} / \mathrm{m}^{3}$. Long-term exposure to lower concentrations of spores can still result in the development of an occupational allergy. The use of PPE and frequent measurement of airborne mold spores are fundamental to reduce exposure of library staff to allergens.

Due to a lack in precise regulations for exposure limits, airborne mold spores are poorly and rarely detected in libraries and in several other indoor environments. However, it is clear that exposure to high levels $\left(>10^{5}\right.$ spores per $\mathrm{m}^{3}$ ) of airborne spores for $8 \mathrm{~h}$ a day could generate moderate effects to the human health. Even though the raising importance of recording the levels of airborne mold spores in libraries, the current methods of determining the total number of airborne mold spores are 
limited and time-consuming. The most common methods require collection of airborne mold spores, sample preparation, manual identification and quantification of using a light microscope. Identifying alternative methods to estimate the likely abundance of airborne mold spores and activities could facilitate more frequent sampling. Measurements of time averages of PM can be obtained by a variety of techniques, such as gravimetric analysis, low-cost sensors, light scattering devices, or other devices with higher precision but with a greater ease of use [1]. Estimating mold spores using PM measurements could be of a potential interest for any indoor environment including both types of pollutants. Furthermore, measuring PMs at the occupational levels could prevent the development of common risks for librarians.

(a)

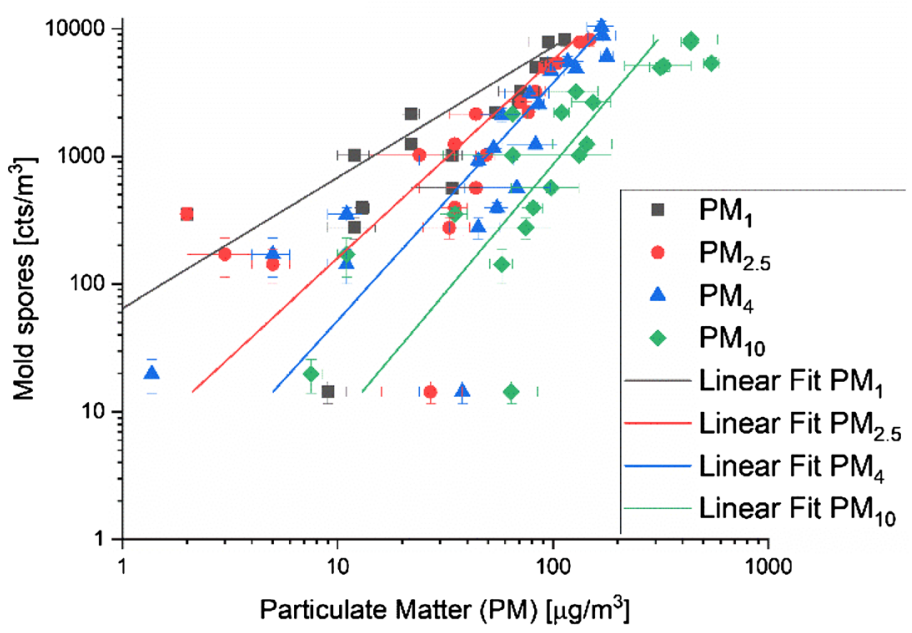

As shown in Fig. $6 a$ and Table 4, the log-scale of the time-averaged values of $\mathrm{PM}_{10}$ and $\mathrm{PM}_{4}$ shows a strong linearity with the counts of mold spores per $\mathrm{m}^{3}\left(R^{2}=0.85\right)$. Even by using the 5 th percentile of the time-averaged data, the highest linear relationship between airborne mold spores and $\mathrm{PM}_{10}$ shows a $R^{2}$ of 0.73 . Penicillium sp. or Aspergillus sp., which are grouped together in analyses of airborne spores have a diameter in the range of 2-5 $\mu \mathrm{m}$. $\mathrm{PM}_{10}$ having a better correlation with respect to $\mathrm{PM}_{4}$ indicates that a large number of measured mold spores might be between 4 and $5 \mu \mathrm{m}$ which shows the highest linearity with airborne mold spores. Such a high linearity has not been previously identified. Values of intercept and slope between the 5th percentile average and the counts of mold spore show a possible higher linearity. However, a better estimation of the linearity between the
Fig. 6 Relationship between the counts of the mold spores and the particulate matter. Particulate matter (PM) are divided into four groups, PM with an average diameter lower than $10\left(\mathrm{PM}_{10}\right)$, lower (b)

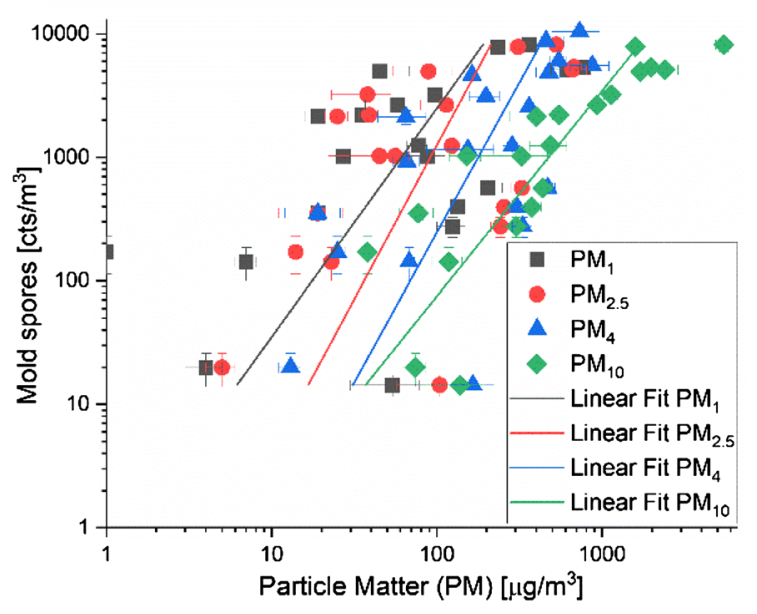

than $4\left(\mathrm{PM}_{4}\right)$, lower than $2.5\left(\mathrm{PM}_{2.5}\right)$, and lower than $1 \mu \mathrm{m}\left(\mathrm{PM}_{1}\right)$. Average and 5 th percentile (5\%) values are shown in (a) and (b), respectively
Table 4 Statistical analysis of the linearity correlation between the mold spores and the $\mathrm{PM}_{2.5}$ measured using a low-cost monitor

\begin{tabular}{lllll}
\hline Parameter & $\mathrm{PM}_{1}$ & $\mathrm{PM}_{2.5}$ & $\mathrm{PM}_{4}$ & $\mathrm{PM}_{10}$ \\
\hline Average & & & & \\
$R^{2}$ & 0.57 & 0.69 & 0.73 & 0.85 \\
Slope & $0.96 \pm 0.23$ & $0.64 \pm 0.12$ & $0.53 \pm 0.11$ & $0.48 \pm 0.12$ \\
Intercept & $-1.76 \pm 0.71$ & $-0.41 \pm 0.37$ & $0.08 \pm 0.07$ & $0.53 \pm 0.25$ \\
Residual sum squares & 21.1 & 13.3 & 8.57 & 5.73 \\
Spearman's rank coefficient & 0.69 & 0.73 & 0.77 & 0.83 \\
5th percentile & & & & \\
$R^{2}$ & 0.45 & 0.58 & 0.67 & 0.73 \\
Slope & $0.54 \pm 0.17$ & $0.41 \pm 0.15$ & $0.41 \pm 0.13$ & $0.61 \pm 0.09$ \\
Intercept & $0.16 \pm 0.15$ & $0.75 \pm 0.41$ & $1.03 \pm 0.37$ & $0.87 \pm 0.22$ \\
Residual sum squares & 6.35 & 4.93 & 3.22 & 1.86 \\
Spearman's rank coefficient & 0.61 & 0.69 & 0.71 & 0.77 \\
\hline
\end{tabular}


5th percentile or the total average of $\mathrm{PM}_{10}$ or $\mathrm{PM}_{4}$ and the mold spore can be achieved analyzing a higher number of cases. In any case, when evaluating the indoor air quality of a library, one could estimate a rise in airborne mold spores when high levels of $\mathrm{PM}_{10}$ or $\mathrm{PM}_{4}$, both as a timeaverage or as spikes, are achieved. A remarkable result visible in Fig. 6 and in Table 4 is that the highest Spearman's rank coefficient between airborne mold spores and particulate matter is obtained by considering $\mathrm{PM}_{10}$. This might indicate that airborne mold spores detected in the libraries could be of a size between 4 and $10 \mu \mathrm{m}$. Moreover, even though the type of mold spores could be limited for two activities (Fig. 4), in a common library, many kinds of bioaerosol could be several. Therefore, measuring the PM could be solely a rough estimation of the possible presence of airborne mold spores in specific activities, such as working with rare and old books.

\subsection{Metal dusts}

The main source of metals in dust is thought to be the outdoor environment. In the case of libraries, books are potential endogenous sources of metals. Airborne metal PM can be generated by opening "old" books since metalbased nanoparticles are used in the preservation procedures for books. Several types of preservation procedures are currently available; however, the most common use $\mathrm{Ag}, \mathrm{Zn}, \mathrm{Ca}, \mathrm{Ba}$, and Ti. These six chemical elements were measured in the collected dust of all PM sizes. Collected

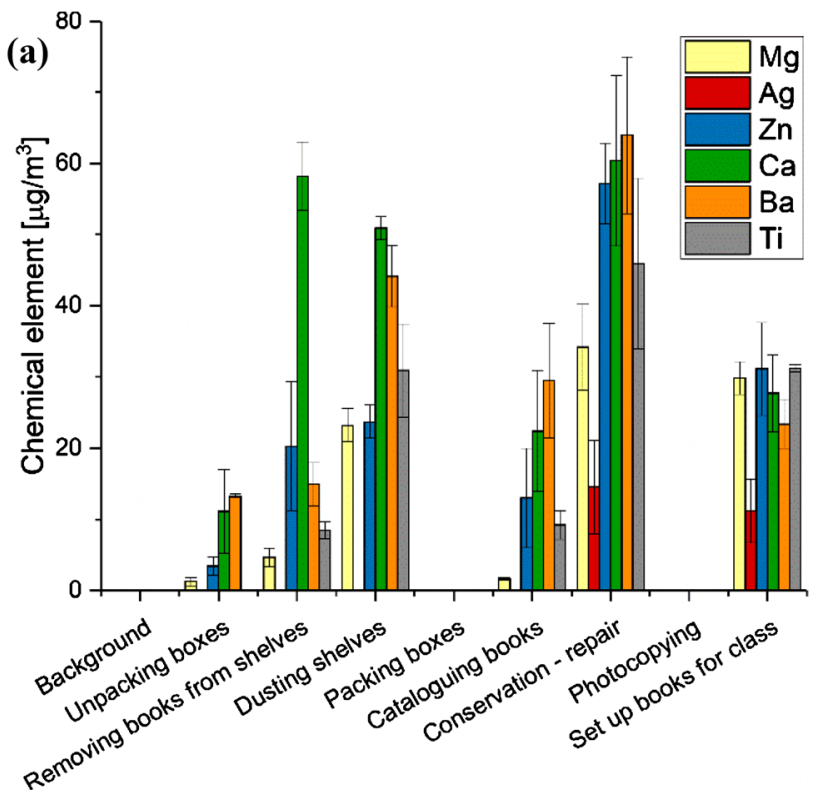

Fig. 7 Levels of chemical elements contained in the dust collected per each activity studied (a) and the correlation (Spearman's correlation) between the chemical elements and different bins in PM dusts on filters were manually weighted by performing a gravimetric analysis; the weights are compared to the average $\mathrm{PM}_{10}$ measured using the DustTrak. The difference between the two measurements is, on average, $5 \%$. The values measured using the gravimetric analysis are higher than the values obtained by real-time measurements only for the activity of dusting shelves and unpacking boxes. This result indicates that, for the other cases, metal dusts are of size smaller than $10 \mu \mathrm{m}$.

As shown in Fig. 7a, all the activities but "packing boxes" and "photocopying" produce metal dusts. $\mathrm{Mg}, \mathrm{Zn}, \mathrm{Ca}, \mathrm{Ba}$, and Ti were detected in the dust collected in all the activities producing some metal dust. Ag was found only in activities involving the use of books older than 100 years. The presence of silver in the library dust could be linked to the preservation procedure used for old books. Other activities such as "removing books from shelves" involve the handling of books of the seventeenth and of the eighteenth century. In this case, books have been not opened but briefly checked and browsed likely generating less Ag-containing dust. High standard errors are found for each case likely due to differences in average age of the books and box origin. Donation boxes are be sent from various locations worldwide. When the origin of the box is a polluted area, the count of chemical elements increases. Positive values of most of the chemical elements for the majority of the activities are concerning for the health of librarians, technicians, or students working in a library especially since these metals are in the nanosize range.

(b)

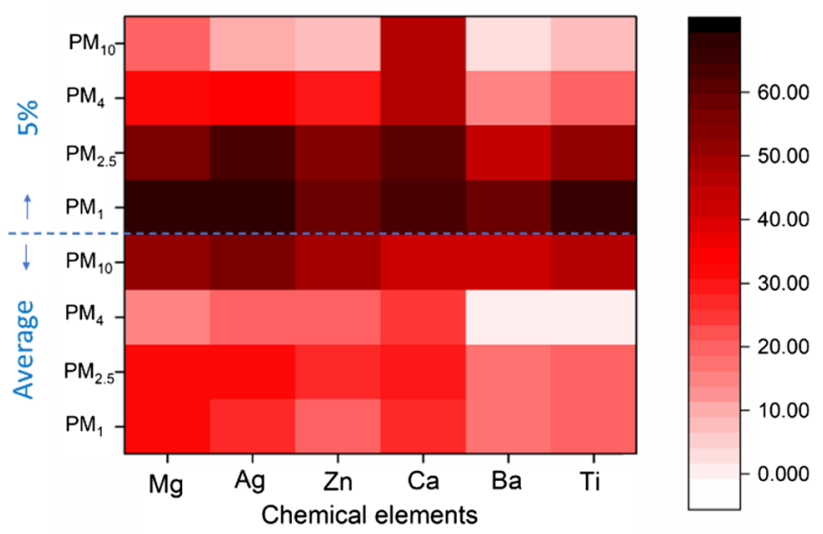

$\left(\mathrm{PM}_{1}, \mathrm{PM}_{2.5}, \mathrm{PM}_{4}\right.$, and $\left.\mathrm{PM}_{10}\right)(\mathbf{b})$. The exposure limits of metal nanoparticles are not reported since much above the shown levels 
Since it was not possible to segregate the chemical elements into size bins, a Spearman's correlation is performed for chemical elements and different sizes of PM, shown in Fig. 7b.

The highest percentages of correlation are determined for two cases: (1) in the average values of $\mathrm{PM}_{10}$, and (2) in the average values of the 5 th percentile of $\mathrm{PM}_{1}$. These two results indicate that metal nanoparticles are likely emitted by sudden activities, such as opening a box, quickly browsing a book, or removing a book from a shelf (Fig. 2a, b). Thus, library staff while performing most of their activities need to increase their care in sudden movements. Another important result recognizable from Fig. $7 \mathrm{~b}$ is the determination that most of the metal dusts are of a diameter lower than 2.5 and $1 \mu \mathrm{m}$. As a consequence, if half of the metal dusts measured are lower than $1 \mu \mathrm{m}$ in diameter, silver highly would exceed its occupation exposure limitations of $0.19 \mu \mathrm{g} / \mathrm{m}^{3}$. Furthermore, $15 \mathrm{~min}$ as short-term exposure limit (STEL) of $Z n$ and Ca is $2 \mathrm{mg} / \mathrm{m}^{3}$. Even though the limitation has not been surpassed, repetitive short-term exposures to concentrations of about $0.5 \mathrm{mg} / \mathrm{m}^{3}$ could potentially contribute to development of occupational diseases.

These results indicate the importance of designing local exhaust ventilation in locations where performing most of the activities involves the management and the handling of books. Each librarian is estimated to spend about $407 \mathrm{~h}$ /year unpacking donation boxes, $110 \mathrm{~h}$ /year preserving books, and $165 \mathrm{~h} /$ year dusting the shelves. Chronic exposure combined with the dangers in exposure to metal nanoparticles highlights the importance of protection from exposure to aerosolized dusts during tasks which generated high levels of dust.

\section{Conclusion}

The evaluation of the indoor air quality of common university libraries is lacking in the literature. Our results demonstrate exposure to PM containing metals and mold spores during common tasks which can contribute the development of occupational diseases. In this project, we determine that the activities of conservation and repair, removing books from the shelves, and unpacking donation boxes produce the highest content of average particulate matter (PM). For instance, PM with the largest analyzed size, $10 \mu \mathrm{m}$, are about 300,250 , and $200 \mu \mathrm{g} / \mathrm{m}^{3}$ in these activities. The importance of real-time measurements is shown by the several spikes in PMs of any size while performing any of the activity that a librarian typically does. In particular, some peaks in PMs are high and contribute to cumulative, chronic exposure.
In a library, PMs are expected to contain airborne mold spores and metal dusts. Books are mostly made of paper that can serve as a substrate for mold growth. Preservation and manufacturing procedure of paper can use some nanoparticles made of metals. In one of the three facilities tested, the identification of Penicillium sp. on books and the presence of these books as an internal, point source of spores suggest that this contamination was the primary contributor to the airborne spores sampled during the time air sampling was performed. For the other facilities, the mold type is unknown but the small spore size suggests Penicillium or Aspergillus sp. The highest number of mold spores in the air is found in the activities with the highest amount of $\mathrm{PM}_{10}$ and $\mathrm{PM}_{4}$, which are conservation and repair, unpacking the donation boxes, removing books from the shelves, and dusting the shelves. The highest count per $\mathrm{m}^{3}$ of airborne mold spore is about 9000 . Due to a lack in regulations for the exposure of any type of mold spores, it is challenging to determine a possible impact to the health of a librarian. The lowest observed effect levels in asthmatic patients allergic to Penicillium and Aspergillus sp. is $10^{4}$ spores $/ \mathrm{m}^{3}$. In a healthy person, respiratory symptoms and airway inflammation appeared at exposure levels of $10^{5} \mathrm{spores} / \mathrm{m}^{3}$. As a consequence, even if the levels determined in this project are lower than the exposure limits, chronic exposures at levels lower but close to the exposure limits can pose health risks for librarians.

Metal dusts show the highest count when collected from a conservation and repair activity. In this activity, books are invasively treated; therefore, any materials present on the surface of each page of a book can be aerosolized and inhaled. If even a tenth of the metal dusts measured have a diameter lower than $1 \mu \mathrm{m}$, while performing conservation and repair, levels of silver are highly exceeding the exposure limit of $0.19 \mu \mathrm{g} / \mathrm{m}^{3}$. As a consequence, designing local exhaust ventilation would be fundamental in locations where a librarian performs the activity of conservation and repair.

Another outcome of this project is the identification of a possible correlation between airborne mold spores and PM. In the libraries sampled, we determine a high linearity $\left(R^{2}=0.85\right)$ between the average of the total minuteby-minute data collected for $\mathrm{PM}_{10}$ and $\mathrm{PM}_{4}$ in any of the librarian's activities considered. The Spearman's rank coefficient is higher than the 0.70 between each metal measured and the average of the 5th percentile of the minuteby-minute data collected for $\mathrm{PM}_{1}$. Therefore, one could estimate the airborne mold spores and the metal dusts in a typical library by measuring the time-averaged $\mathrm{PM}_{10}$ and the spikes of $\mathrm{PM}_{1}$, respectively. Validation of this approach would require additional sampling of libraries. Moreover, future development could relate to the implementation 
of a more accurate real-time measurements for bioaerosols in order to generate a better estimate of airborne mold spores. Indeed, more attention to the occupational exposure of librarian would deserve a larger space in the upcoming literature references.

Acknowledgements The authors would like to acknowledge Dr. Matthew Jeronimo for suggesting useful improvements to the project, helping with the use of some devices, and for accurately reviewing the manuscript. Besides, the authors are grateful to libraries' directors and managers Adolfo Tarango, Katherine Kalsbeek, Katherine Hill, and Taylor Sally.

Availability of data and materials Data can be shared under request.

Code availability No computational code has been used in this project.

\section{Declarations}

Conflict of interest The authors do not recognize any conflict of interest.

Open Access This article is licensed under a Creative Commons Attribution 4.0 International License, which permits use, sharing, adaptation, distribution and reproduction in any medium or format, as long as you give appropriate credit to the original author(s) and the source, provide a link to the Creative Commons licence, and indicate if changes were made. The images or other third party material in this article are included in the article's Creative Commons licence, unless indicated otherwise in a credit line to the material. If material is not included in the article's Creative Commons licence and your intended use is not permitted by statutory regulation or exceeds the permitted use, you will need to obtain permission directly from the copyright holder. To view a copy of this licence, visit http://creativecommons. org/licenses/by/4.0/.

\section{References}

1. Amaral SS, De Carvalho JA, Costa MAM, Pinheiro C (2015) An overview of particulate matter measurement instruments. Atmosphere 6:1327-1345

2. American Conference of Governmental Industrial Hygienists $\left(\right.$ ACGIH $\left.^{\circledR}\right)$ (1984) Threshold limit values for chemical substances in the work environment

3. Amornkitbamrung L, Mohan T, Hribernik S, Reichel V, Faivre D, Gregorova A, Engel P, Kargl R, Ribitsch V (2015) Polysaccharide stabilized nanoparticles for deacidification and strengthening of paper. RSC Adv 5:32950-32961

4. Anders M (2006) Book and paper preservation. Wiley Online Library

5. Apetrei IC, Drăgănescu GE, Popescu IT, Carp-Cărare C, Guguianu E, Mihăescu T, Ştefanache A, Creţu C, Patraş X (2009) Possible cause of allergy for the librarians: books manipulation and ventilation as sources of fungus spores spreading. Aerobiologia 25:159-166

6. Baldelli A, Jeronimo M, Tinney M, Bartlett K (2020) Real-time detection of formaldehyde emissions in a gross anatomy laboratory. SN Appl Sci 2:739
7. Baldelli A, Jeronimo M, Loosley B, Owen G, Welch I, Bartlett K (2020) Particle matter, volatile organic compounds, and occupational allergens: correlation and sources in laboratory animal facilities. SN Appl Sci 2(10):1-14

8. Baxter DM, Perkins JL, McGhee CR, Seltzer JM (2005) A regional comparison of mold spore concentrations outdoors and inside "clean" and "mold contaminated" Southern California buildings. J Occup Environ Hyg 2:8-18

9. Block S (1953) Humidity requirements for mold growth. Appl Microbiol 1:287

10. Bondarenko T (2016) Profile of sensibilisation to major and minor components of domestic allergens in patients with allergic rhinitis and helminthosis. Acta Та АЛЕРГІЯ, 2

11. Burge HP, Boise J, Solomon WR, Bandera E (1978) Fungi in libraries: an aerometric survey. Mycopathologia 64:67-72

12. Chow JC, Yang X, Wang X, Kohl SD, Hurbain PR, Chen LA, Watson JG (2015) Characterization of ambient PM10 bioaerosols in a California agricultural town. Aerosol Air Qual Res 15:1433-1447

13. El-Feky OM, Hassan EA, Fadel SM, Hassan ML (2014) Use of ZnO nanoparticles for protecting oil paintings on paper support against dirt, fungal attack, and UV aging. J Cult Herit 15:165-172

14. Esworthy R (2013) Air quality: EPA's 2013 changes to the particulate matter (PM) standard. Library of Congress, Congressional Research Service

15. Feofilova E, Ivashechkin A, Alekhin A, Sergeeva YE (2012) Fungal spores: dormancy, germination, chemical composition, and role in biotechnology. Appl Biochem Microbiol 48:1-11

16. Ferraz-Albani LA, Baldelli A, Knapp CJ, Jäger W, Vehring R, Nobes DS, Olfert JS, Kostiuk LW (2017) Enhanced evaporation of microscale droplets with an infrared laser. J Heat Transf 139(1):011503

17. Giorgi R, Bozzi C, Dei L, Gabbiani C, Ninham BW, Baglioni P (2005) Nanoparticles of $\mathrm{Mg}(\mathrm{OH})_{2}$ : synthesis and application to paper conservation. Langmuir 21:8495-8501

18. Heusinkveld HJ, Wahle T, Campbell A, Westerink RH, Tran L, Johnston H, Stone V, Cassee FR, Schins RP (2016) Neurodegenerative and neurological disorders by small inhaled particles. Neurotoxicology 56:94-106

19. Ion R-M, Doncea SM, Ion M-L, Rădiţoiu V, Amăriuţei V (2013) Surface investigations of old book paper treated with hydroxyapatite nanoparticles. Appl Surf Sci 285:27-32

20. Jones AP (1999) Indoor air quality and health. Atmos Environ 33:4535-4564

21. Kelman BJ, Robbins CA, Swenson LJ, Hardin BD (2004) Risk from inhaled mycotoxins in indoor office and residential environments. Int J Toxicol 23:3-10

22. Kendrick $B$ (2017) The fifth kingdom. Hackett Publishing

23. Koton S, Molshatzki N, Myers V, Broday DM, Drory Y, Steinberg DM, Gerber Y (2013) Cumulative exposure to particulate matter air pollution and long-term post-myocardial infarction outcomes. Prev Med 57:339-344

24. Lee K, Hahn EJ, Riker C, Head S, Seithers P (2007) Immediate impact of smoke-free laws on indoor air quality. South Med J 100:885-889

25. Lin W-R, Chen Y-H, Lee M-F, Hsu L-Y, Tien C-J, Shih F-M, Hsiao S-C, Wang P-H (2016) Does spore count matter in fungal allergy? The role of allergenic fungal species. Allergy Asthma Immunol Res 8:404-411

26. Liu S, Zhou Y, Liu S, Chen X, Zou W, Zhao D, Li X, Pu J, Huang L, Chen J (2017) Association between exposure to ambient particulate matter and chronic obstructive pulmonary disease: results from a cross-sectional study in China. Thorax 72:788-795

27. Lloyd H, Bendix C, Brimblecombe P, Thickett D (2007) Dust in historic libraries. Museum Microclimates 135-144 
28. Meklin T, Reponen T, McKinstry C, Cho S-H, Grinshpun SA, Nevalainen A, Vepsäläinen A, Haugland RA, LeMasters G, Vesper SJ (2007) Comparison of mold concentrations quantified by MSQPCR in indoor and outdoor air sampled simultaneously. Sci Total Environ 382:130-134

29. Monn C, Becker S (1999) Cytotoxicity and induction of proinflammatory cytokines from human monocytes exposed to fine (PM2.5) and coarse particles $\left(\mathrm{PM}_{10-2.5}\right)$ in outdoor and indoor air. Toxicol Appl Pharmacol 155:245-252

30. Poggi G, Toccafondi N, Melita LN, Knowles J, Bozec L, Giorgi R, Baglioni P (2014) Calcium hydroxide nanoparticles for the conservation of cultural heritage: new formulations for the deacidification of cellulose-based artifacts. Appl Phys A 114:685-693

31. Righi E, Aggazzotti G, Fantuzzi G, Ciccarese V, Predieri G (2002) Air quality and well-being perception in subjects attending university libraries in Modena (Italy). Sci Total Environ 286:41-50

32. Rushdy AM, Wahba WN, Abd-Aziz MS, Samahy ME, Kamel S (2017) A comparative study of consolidation materials for paper conservation. Int J Conserv Sci 8(3):441-452

33. Sahu V, Gurjar BR (2019) Spatio-temporal variations of indoor air quality in a university library. Int J Environ Health Res 1-16

34. Segers FJ, van Laarhoven KA, Huinink HP, Adan OC, Wösten HA, Dijksterhuis J (2016) The indoor fungus Cladosporium halotolerans survives humidity dynamics markedly better than Aspergillus niger and Penicillium rubens despite less growth at lowered steady-state water activity. Appl Environ Microbiol 82:5089-5098
35. Srimuruganandam B, Nagendra SMS (2010) Analysis and interpretation of particulate matter-PM10, PM2.5 and PM1 emissions from the heterogeneous traffic near an urban roadway. Atmos Pollut Res 1:184-194

36. Van Slyck AA (2001) The librarian and the library: why place matters. Libr Cult 36:518-523

37. Weaver-Meyers PL, Stolt WA, Kowaleski B (1998) Controlling mold on library materials with chlorine dioxide: an eight-year case study. J Acad Librariansh 24:455-458

38. Williams AM, Phaneuf DJ, Barrett MA, Su JG (2019) Short-term impact of PM2.5 on contemporaneous asthma medication use: behavior and the value of pollution reductions. Proc Natl Acad Sci 116:5246-5253

39. Wu Y, Lu Y, Chou D-C (2018) Indoor air quality investigation of a university library based on field measurement and questionnaire survey. Int J Low-Carbon Technol 13:148-160

40. Yang $Z$ (2017) Indoor air pollution and preventions in college libraries. In: IOP Conference Series: Earth and Environmental Science, IOP Publishing, p 012076

Publisher's Note Springer Nature remains neutral with regard to jurisdictional claims in published maps and institutional affiliations. 